\title{
Multi-centennial summer and winter precipitation variability in southern South America
}

\author{
R. Neukom, ${ }^{1,2}$ J. Luterbacher, ${ }^{3}$ R. Villalba, ${ }^{4}$ M. Küttel, ${ }^{1,2,5}$ D. Frank, ${ }^{2,6}$ P. D. Jones, ${ }^{7}$ \\ M. Grosjean, ${ }^{1,2}$ J. Esper, ${ }^{8}$ L. Lopez, ${ }^{4}$ and H. Wanner ${ }^{1,2}$
}

Received 20 April 2010; revised 9 June 2010; accepted 16 June 2010; published 31 July 2010.

[1] We present the first spatially and temporally highly resolved gridded reconstruction of multi-centennial precipitation variability for southern South America (SSA). A novel reconstruction approach of deriving 10,000 ensemble members based on varying predictor networks and methodological settings allows the identification of spatiotemporal changes in SSA precipitation and associated uncertainties. The summer and winter reconstructions back to AD 1498 and AD 1590, respectively, provide new evidence for multi-centennial increase in summer precipitation and an opposing decrease in winter precipitation into the 20th century. The drying in winter is significant over large parts of SSA, whereas the patterns for summer, possibly representing convective rainfall, have displayed high spatial variability. The fact that such long-term seasonal and spatial changes have occurred in the past, underlines the complex form that hydroclimatic variability might have in the future. This emphasizes the need for careful adaptation strategies as governments become attuned to the realities of climate change. Citation: Neukom, R., J. Luterbacher, R. Villalba, M. Küttel, D. Frank, P. D. Jones, M. Grosjean, J. Esper, L. Lopez, and H. Wanner (2010), Multi-centennial summer and winter precipitation variability in southern South America, Geophys. Res. Lett., 37, L14708, doi:10.1029/2010GL043680.

\section{Introduction}

[2] The fundamental dependence of all living beings on water makes projected spatial, temporal, and seasonal variations in water-supply a critical factor in determining how well societies can adapt to on-going climate change. Furthermore, changes in the seasonal patterns and cycles may also have significant consequences on snow versus rain totals, runoff rates and ecosystem functioning and accord-

\footnotetext{
${ }^{1}$ Institute of Geography, Climatology and Meteorology, University of Bern, Bern, Switzerland.

${ }^{2}$ Oeschger Centre for Climate Change Research, University of Bern, Bern, Switzerland.

${ }^{3}$ Department of Geography, Climatology, Climate Dynamics and Climate Change, Justus Liebig University Giessen, Giessen, Germany.

${ }^{4}$ Instituto Argentino de Nivología y Glaciología y Ciencias Ambientales, CONICET, Mendoza, Argentina.

${ }^{5}$ Department of Earth and Space Sciences, University of Washington, Seattle, Washington, USA.

${ }^{6}$ Swiss Federal Research Institute WSL, Birmensdorf, Switzerland.

${ }^{7}$ Climatic Research Unit, School of Environmental Sciences, University of East Anglia, Norwich, UK.

${ }^{8}$ Department of Geography, Johannes Gutenberg University, Mainz, Germany.
}

Copyright 2010 by the American Geophysical Union. 0094-8276/10/2010GL043680 ingly require new agricultural practices. Knowledge of past variations in the hydrological cycle is of crucial importance for placing recent moisture changes on local, regional and continental scales into a long term context and understanding the processes driving these changes [Jansen et al., 2007; Jones et al., 2009]. However, gridded (proxy based) reconstructions of moisture variability are still rare and predominantly restricted to the Northern Hemisphere [e.g., Cook et al., 2004, 2010; Pauling et al., 2006], mostly due to the limited number of annually-resolved precipitation-sensitive proxy data available.

[3] Due to the modulating effect of the Andes and the influence of distinct oceanic and atmospheric patterns such as the El Niño-Southern Oscillation, the Southern Annular Mode, and the South American Summer Monsoon, South America's precipitation regime is particularly variable [e.g., Garreaud et al., 2009] (see also Figure 1). Considering that South America's economies and societies are highly dependent on hydropower generation and irrigation [Magrin et al., 2007], it is important to quantify past and present precipitation variability and extremes in this region as detailed as possible.

[4] In southern South America (SSA, south of $20^{\circ} \mathrm{S}$ ), the number of precipitation-sensitive records from paleoclimatic archives, such as tree rings [Boninsegna et al., 2009], documentary evidence [e.g., Neukom et al., 2009] and lake sediments [e.g., Moy et al., 2009] has significantly increased within the last decade. Herein, we combine the currently available annually or higher resolved paleoclimatic evidence with long instrumental data to derive gridded $\left(0.5^{\circ} \times\right.$ $0.5^{\circ}$ ), seasonal SSA precipitation reconstructions. Separately reconstructed austral summer and winter precipitation fields with associated uncertainties are provided back to the late 15th (summer) and 16th (winter) centuries. These reconstructions represent the first spatially explicit estimates of large-scale SSA precipitation prior to the instrumental era.

\section{Data and Methods}

\subsection{Instrumental Calibration Data}

[5] We use the new $0.5^{\circ} \times 0.5^{\circ}$ and monthly resolved CRU TS 3 gridded precipitation dataset (updated from Mitchell and Jones [2005]) covering 1901-2006 as instrumental target. The SSA region is defined as all land grid cells between $20^{\circ} \mathrm{S}-55^{\circ} \mathrm{S}$ and $80^{\circ} \mathrm{W}-30^{\circ} \mathrm{W}$. The reconstructions are performed for austral summer (December to February; DJF) and winter (June to August; JJA). These seasons were selected based upon tests of the optimal seasonal response windows of the proxy records (not shown). We used the period 1931-1995 for generating ensemble calibration/verification reconstructions. Before 1931, the 


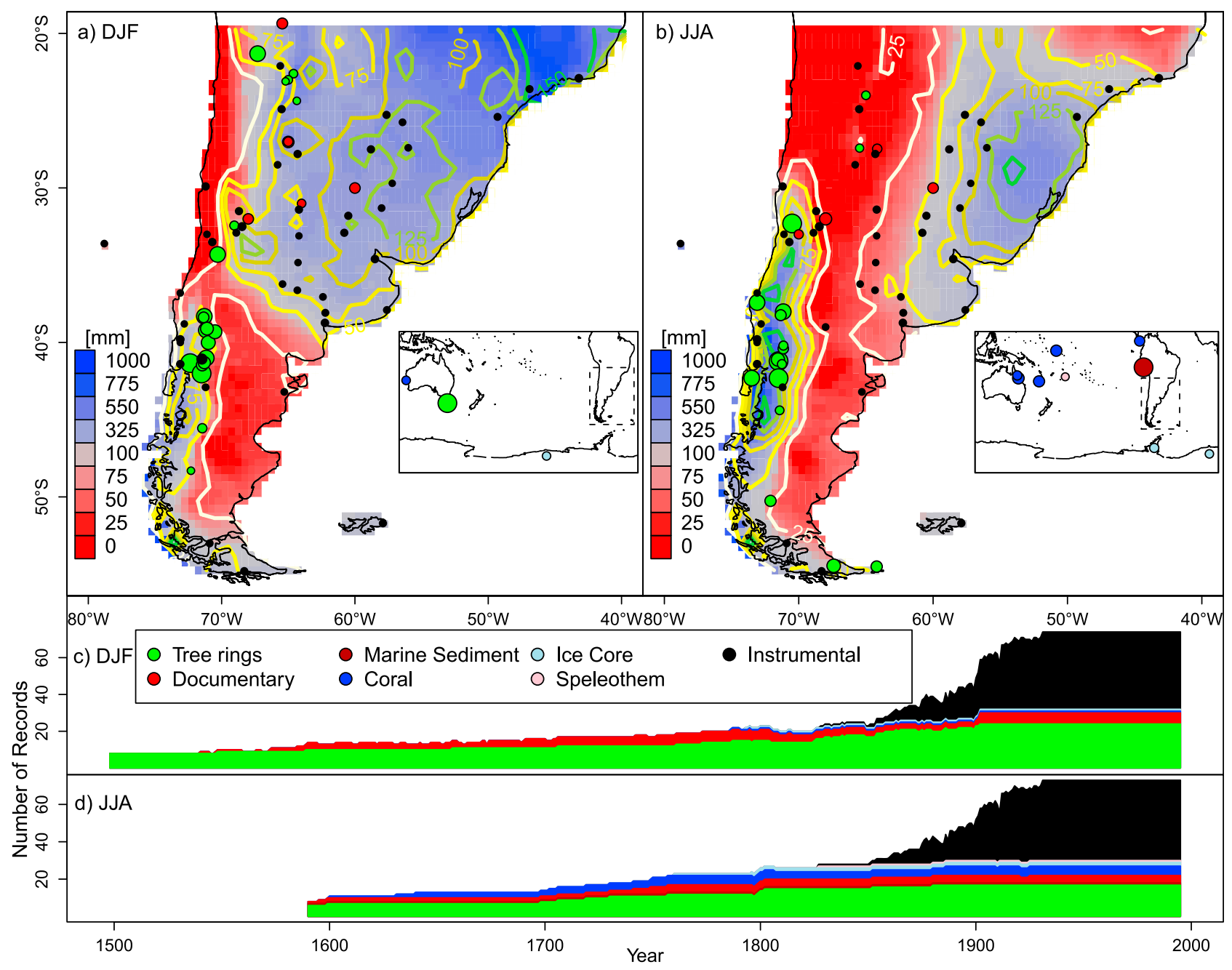

Figure 1. Locations of the predictors used for the (a) summer and (b) winter reconstructions. The size of the circles represents the lengths of the series (smallest: 90 years, largest: $>1000$ years). The reconstruction area is marked by a dashed margin in the small maps. Shaded colors in the SSA-maps represent the 1931-1995 average precipitation [mm]. Notice the different scale in the reddish and bluish colors. The contour lines indicate precipitation standard deviations 1931-1995 [mm]. Temporal evolution of the number of predictors used for (c) summer and (d) winter.

quality of the gridded data is reduced due to a strong decline in available station data [see, e.g., Garreaud et al., 2009; Neukom et al., 2010].

\subsection{Predictor Data}

[6] As a basis for the selection of the predictors, we use the SSA proxy network established by Neukom et al. [2010] consisting of 144 natural proxies (tree rings, ice cores, corals, speleothems, lake and marine sediments) and documentary records sensitive to SSA climate. From this network, the records significantly correlating with the instrumental target in the overlapping period are selected (see auxiliary material). ${ }^{1}$ Additionally, long instrumental precipitation series from SSA (GHCN [Peterson and Vose, 1997]) with data prior to 1920 and covering at least 50 years within the 1931-1995 calibration window are included as predictors. Table S1 (Table S2) presents the final predictor network consisting of 33 (31) proxy records and 41 (42) instrumental

\footnotetext{
${ }^{1}$ Auxiliary materials are available in the HTML. doi:10.1029/ 2010GL043680.
}

series for summer (winter). The locations of the proxies as well as their temporal availability are shown in Figure 1. Some of the proxy records are related to SSA precipitation by large-scale teleconnection patterns [e.g., Villalba et al., 1997]. Neukom et al. [2010] showed that consideration of such remote proxies can substantially improve SSA climate reconstructions. The selected predictors are fully independent from those used by Neukom et al. [2010] to reconstruct seasonal temperature fields. Missing values $(<0.1 \%)$ in the predictor matrices during the calibration period were estimated using an EOF (empirical orthogonal functions) based algorithm [Neukom et al., 2010; Scherrer and Appenzeller, 2006].

\subsection{Reconstruction Methodology}

[7] We performed the reconstructions using ordinary least squares principal component regression (PCR) [e.g., Küttel et al., 2010; Luterbacher et al., 2002, 2004; Neukom et al., 2010; Pauling et al., 2006; Xoplaki et al., 2005]. In PCR, transfer functions between a certain number of principal components of the predictor and instrumental data 
are established in the calibration period using multiple linear regressions. This relationship is then used to predict the values of the predictand in the reconstruction period based on the assumption that the relationship is linear and stable over time (see Luterbacher et al. [2002] for a detailed discussion of the methodology). As the number of available predictors changes over time (Figures $1 \mathrm{c}$ and $1 \mathrm{~d}$ and Tables $\mathrm{S} 1$ and S2), individual regression models are calculated using at each time step the maximum number of available predictors, resulting in a total of 88 (86) statistical models for winter (summer). To avoid variance biases due to the decreasing number of predictors back in time [e.g., Cook et al., 2004; Frank et al., 2007], the reconstructions of each model were scaled to the variance of the instrumental target in the 1931-1995 overlap period. It is well known that the selection of the predictors, calibration and verification periods, as well as parameters within the reconstruction methodology influence reconstructed values [e.g., Rutherford et al., 2005; Wahl and Ammann, 2007]. Yet, as objective selection criteria are largely missing, we derive an ensemble of 10,000 reconstructions, with each member being based on different reconstruction settings [see also Frank et al., 2010; van der Schrier et al., 2007]. The settings are varied for each ensemble member by randomly (1) withholding five predictors from the predictor dataset; (2) choosing 43 (nonsuccessive) years (corresponds to two thirds of all years) within the 1931-1995 overlap period for calibration. The remaining third (22 years) are used for verification; (3) varying the percentage of total variance explained by the retained PCs between $60 \%$ and $95 \%$, corresponding to 8 (1) to 39 (13) PCs of the instrumental (predictor) data matrix. This is done individually for the instrumental as well as predictor matrices.

[8] Even with these settings, not all parameters in the reconstruction methodology are objectively considered. For example, withholding five predictors is a compromise between allowing reconstructions to be derived reasonably far back in time and introducing sufficient variability between ensemble members. Further, the range of PCs chosen to be retained is somewhat arbitrary, however representing the range commonly used in comparable reconstructions. Consequently, we obtain a distribution function for the reconstructed values, rather than a single value as for conventional methodologies. For the reconstruction of precipitation $P$ at each location and time step, median values of the ensemble members (see Figure S1) are calculated. In order to minimize variance biases due to changes in the correlations between the 10,000 realizations, $P$ is variance adjusted using the RUNNINGr-adjustment described by Frank et al. [2007]. It must be noted that uncertainties that may arise from systematic methodological biases, such as variance losses and mean biases [e.g., Smerdon et al., 2010, and references therein], are not captured by our ensemble approach. Pre- dictor data availability allows the reconstruction of SSA summer (winter) precipitation back to AD 1498 (1590), where eight predictors are available. Other reconstruction techniques were also tested (composite plus scaling and regularized expectation maximization). They yielded similar ensemble means, but lower regression skills and occasionally extreme outliers of single ensemble members [see also Neukom et al., 2010; Wilson et al., 2010]. We therefore confine our analysis to the results of PCR.

\section{Results and Discussion}

[9] The reconstructed spatial precipitation patterns, displayed as century-averaged anomalies relative to the 19311995 mean, indicate that austral summers of the 17th to 19th centuries were in most regions drier than climatology, particularly in the La Plata Basin and Patagonia (Figure 2). Anomalously wet conditions prevailed during this period in the subtropical Andes, north-eastern SSA and Tierra del Fuego. The 16th century shows a different picture with mostly positive (negative) anomalies north (south) of approximately $37^{\circ}$ S. Except for some regions in northern Patagonia, Tierra del Fuego and north-eastern SSA, 17th to 19th century austral winters were generally wetter than climatology. The maps in the bottom row of Figure 2 depict the areas where the 19311995 period was drier (red) or wetter (blue) than all preceding centuries. Dark shadings delineate areas where all of the four (three) previous centuries were significantly $(\mathrm{p}<$ 0.05; Wilcoxon test) drier or wetter than the 1931-1995 summers (winters). Modern summer conditions (1931-1995) are reconstructed to be significantly wetter than any of the preceding centuries' mean over entire Patagonia. Parts of north-western Argentina and north-eastern SSA are in contrast found to be drier. In winter, significant drying can be found across large areas of SSA. The only region where the change is significant and of the same sign in both seasons (dry 1931-1995) is north-western Argentina. Although we have shown how precipitation varies in space throughout time, it is also interesting to assess the temporal changes averaged over particular regions and the entire SSA domain. This is shown in Figure 3 (for alternative illustrations of the ensemble members see Figures S2-S5, statistical skill measures see section S3 and Figures S6-S12 of Text S1). Averaged over SSA, reconstructed summers are generally drier than climatology between $1600-1930$ but slightly wetter in the 16th century. Winter conditions in the 17th to 19th centuries reveal an opposite picture with reconstructed precipitation mostly being above climatology. The robustness of these conclusions clearly changes over time, with the spread of the ensemble members decreasing towards the end of the 19th century when instrumental predictors become increasingly available. As an independent validation, Figure $3 \mathrm{c}$ shows our recon-

Figure 2. Average precipitation anomalies of the 16th (top row, only for summer), 17th (second row), 18th (third row) and 19th (fourth row) centuries relative to the calibration period (1931-1995). Contour lines indicate the average interannual reconstruction uncertainties in the respective century, defined as the root mean squared difference between the ensemble median $P$ and the 5th and 95th percentiles of the ensembles, respectively. All values are shown relative to the instrumental standard deviation 1931-1995 in order to take account of the large regional variations in precipitation within SSA (Figure 1). Fifth row: Areas where all of the four (three) previous centuries were drier or wetter than the 1931-1995 summers (winters). Dark colors indicate significant results $(\mathrm{p}<0.05$; Wilcoxon test). Left: summer; right: winter. 


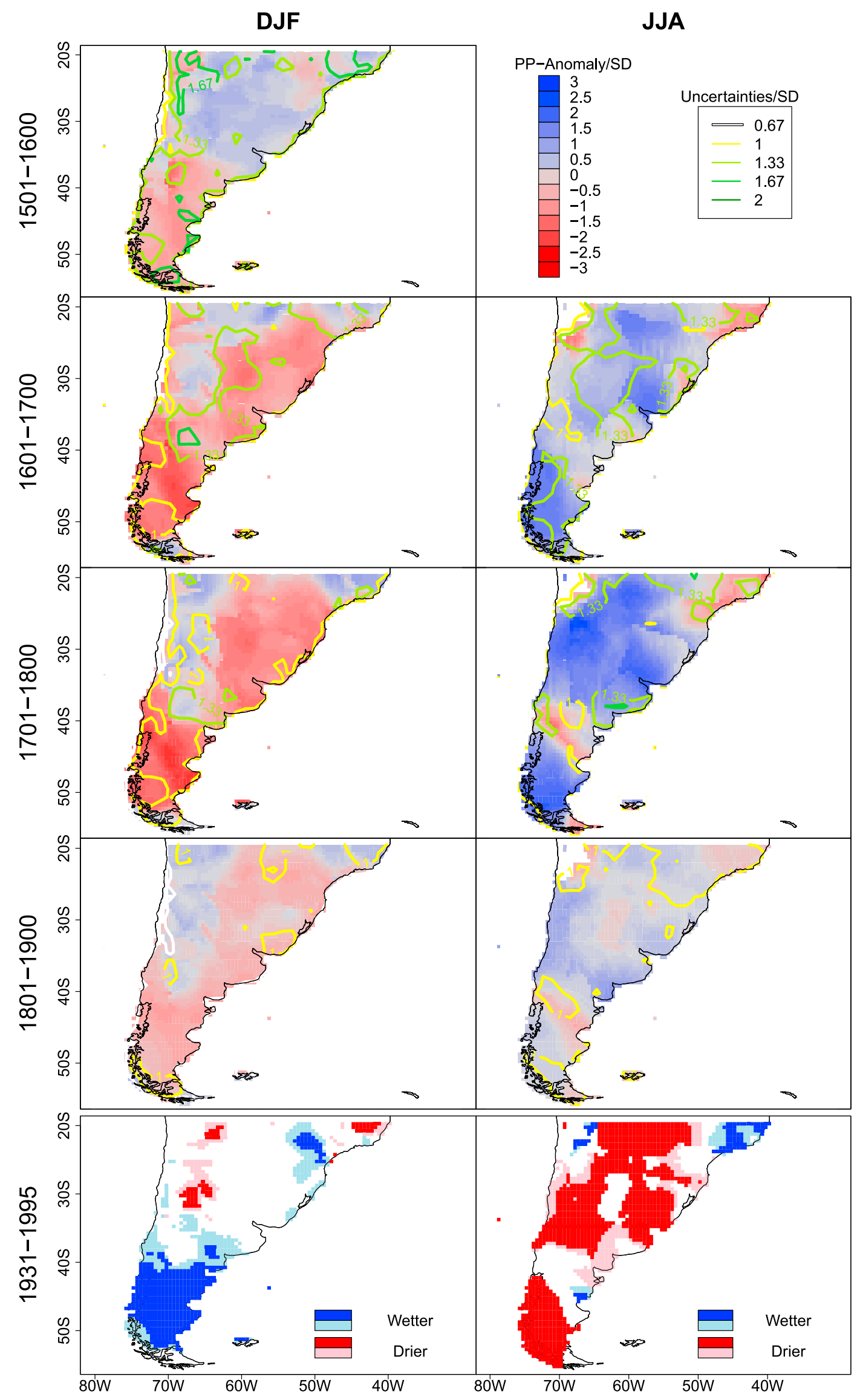

Figure 2 


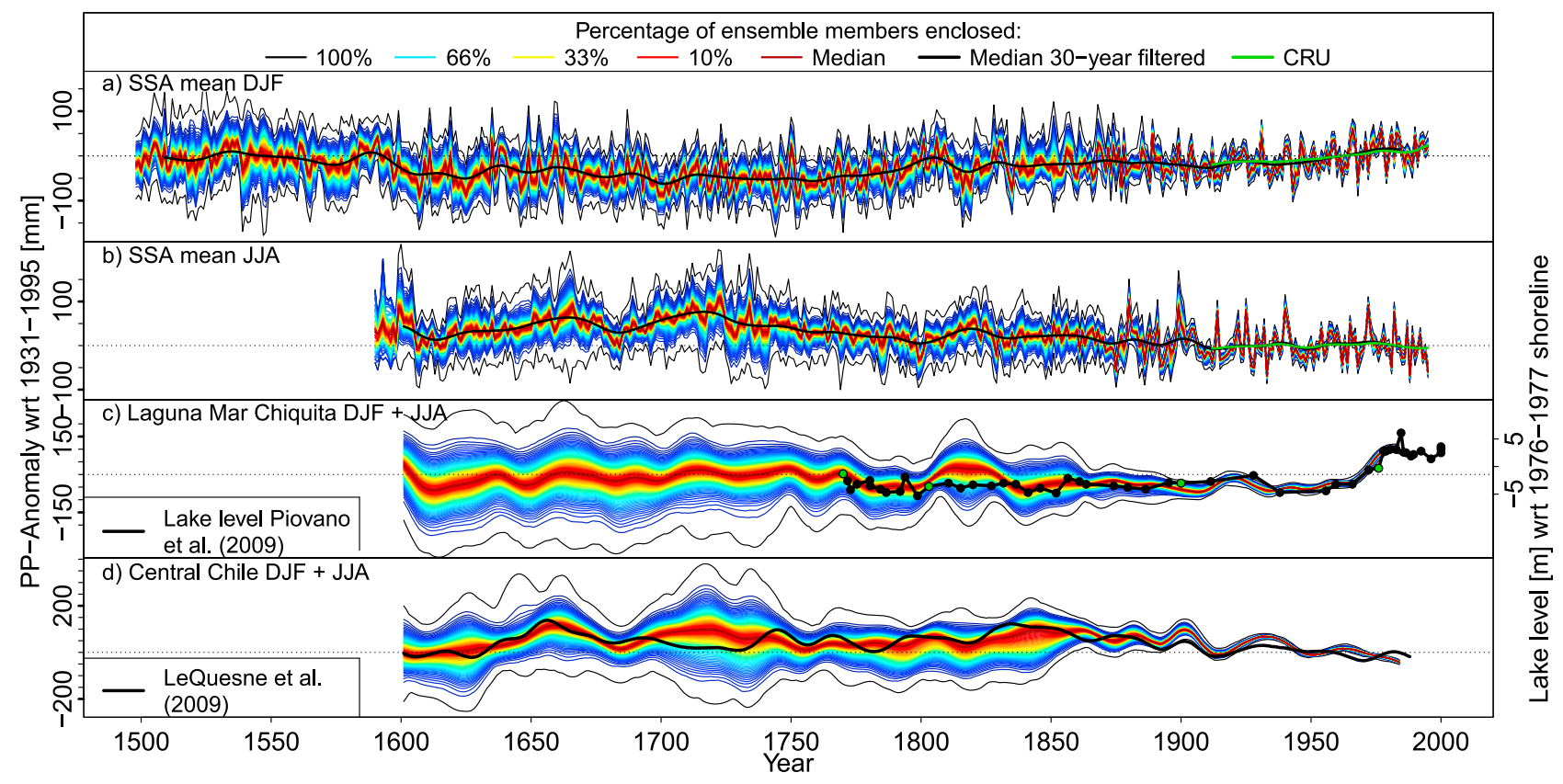

Figure 3. Percentiles of the reconstruction ensembles. Each line represents a percentile. The area between the black lines encloses all (100\%) members; the area between the lowest (1st percentile) and the highest blue lines (99th percentile) encloses $98 \%$ of the members, and so on. SSA mean summer (winter) precipitation reconstruction (a) 1498-1995 and (b) 1590-1995, anomalous to the 1931-1995 average. Bold lines: 30-year Gaussian filtered ensemble median (black) and CRU gridded (green) precipitation. (c) 30-year Gaussian filtered annual precipitation (sum of summer and winter accounting for $63 \%$ of the annual instrumental precipitation totals) in the catchment area of Laguna Mar Chiquita and the lake level reconstruction of Piovano et al. [2009] (black, green points are dated, other dates are linearly interpolated). (d) 30-year filtered Central Chile annual precipitation (sum of summer and winter accounting for $78 \%$ of annual instrumental totals) compared to the results of Le Quesne et al. [2009] (black, 30-year filter).

struction (sum of summer and winter) averaged over the catchment area of the Laguna Mar Chiquita in northern Argentina along with the lake level reconstruction by Piovano et al. [2009] (for methodological details see the auxiliary material). Both curves indicate dry conditions between 1770 and 1950, followed by a sharp increase towards present. The pluvial period in the first half of the 19th century in our reconstruction is, however, not confirmed by the lake level reconstruction. In this period, the spread of our ensemble members is relatively large, indicating reduced reliability of the median values. Figure $3 \mathrm{~d}$ presents our reconstruction (sum of summer and winter) in Central Chile along with the tree-ring based annual precipitation reconstruction of Le Quesne et al. [2009]. Again, the two reconstructions show similar decadal-scale fluctuations and the period with the largest discrepancy (early 18 th century) corresponds to an episode of reduced agreement among ensemble members. Both validations reveal a good agreement over the data rich 20th century, indicating increasing (decreasing) precipitation amounts in the Laguna Mar Chiquita (Central Chile). Further back in time, reconstruction uncertainties (i.e. the spread of the ensemble members) increase and the agreement with the independent reconstructions decreases. We suggest that the dissimilarities are mainly due to the different target seasons (annual vs. sum of summer and winter), the decreasing number of predictors available in the multiproxy reconstructions as well as increasing dating uncertainty and decreasing temporal resolution of the lake sediment record back in time. In Central Chile, the differences may also be due to the different calibration data (instrumental station vs. grid) and calibration periods.

\section{Conclusions and Outlook}

[10] This study represents the first near-continental-scale seasonal precipitation reconstruction within the Southern Hemisphere. Verification statistics and comparison with independent, local datasets indicate that the currently available proxy network allows reasonably assessing variations of large-scale precipitation variability well beyond the 20th century and over wide areas of SSA. The skill of our reconstructions is highest in regions with significant amounts of precipitation falling in the respective seasons and where the coverage with proxy data is high. Some regions, including the most densely populated area of SSA in the north-east, are still very sparsely covered with proxy data, mainly before 1850 . This underlines the need for more high resolution proxy data from SSA. Our reconstructions, together with new temperature [Neukom et al., 2010] and circulation reconstructions, may help to improve our understanding of the influences of atmospheric and oceanic circulation patterns on SSA climate, which again can serve as a base for detection and attribution studies in the area. The multi-centennial moistening trend in austral summer and drying trend in winter towards present represent significant changes to the seasonal cycle and South American climatology. Assessment of societal and economic changes in SSA related to these changes will require further inves- 
tigation. Faced with a changing climate, limited resources, and a growing population, a long-term baseline and assessment of seasonal, spatial, and temporal changes, such as provided by these reconstructions, may be useful to help refine or develop water-allocation agreements.

[11] Acknowledgments. RN is supported by the Swiss NSF through the NCCR Climate. JL acknowledges support by the EU/FP6 integrated project CIRCE (Climate Change and Impact Research: the Mediterranean Environment; \#036961), from the EU/FP7 project ACQWA (Assessing Climate Impacts on the Quantity and Quality of Water, \#212250) and from the DFG Project PRIME (PRecipitation In the past Millennium in Europe) within the Priority Program 'INTERDYNAMIK'. We thank Mariano Masiokas and Eduardo Piovano for providing their data. Many thanks go to all contributors of proxy data and to PAGES for supporting the initiative LOTRED South America. The reviewers made useful comments and suggestions and helped to improve the quality of this study.

\section{References}

Boninsegna, J. A., et al. (2009), Dendroclimatological reconstructions in South America: A review, Palaeogeogr. Palaeoclimatol. Palaeoecol., 281, 210-228, doi:10.1016/j.palaeo.2009.07.020.

Cook, E. R., et al. (2004), Long-term aridity changes in the western United States, Science, 306, 1015-1018, doi:10.1126/science.1102586.

Cook, E. R., et al. (2010), Asian monsoon failure and megadrought during the last millennium, Science, 328, 486-489, doi:10.1126/science. 1185188

Frank, D., J. Esper, and E. R. Cook (2007), Adjustment for proxy number and coherence in a large-scale temperature reconstruction, Geophys. Res. Lett., 34, L16709, doi:10.1029/2007GL030571.

Frank, D., et al. (2010), Ensemble reconstruction constraints of the global carbon cycle sensitivity to climate, Nature, 463, 527-530, doi:10.1038/ nature 08769 .

Garreaud, R. D., et al. (2009), Present-day South American climate, Palaeogeogr. Palaeoclimatol. Palaeoecol., 281, 180-195, doi:10.1016/ j.palaeo.2007.10.032.

Jansen, E., et al. (2007), Palaeoclimate, in Climate Change 2007: The Physical Science Basis. Contribution of Working Group I to the Fourth Assessment Report of the Intergovernmental Panel on Climate Change, edited by S. Solomon et al., pp. 433-497, Cambridge Univ. Press, Cambridge, U. K.

Jones, P. D., et al. (2009), High-resolution palaeoclimatology of the last millennium: A review of current status and future prospects, Holocene, 19, 3-49, doi:10.1177/0959683608098952.

Küttel, M., et al. (2010), The importance of ship log data: Reconstructing North Atlantic, European and Mediterranean sea level pressure fields back to 1750, Clim. Dyn., 34, 1115-1128, doi:10.1007/s00382-0090577-9.

Le Quesne, C., et al. (2009), Long-term glacier variations in the Central Andes of Argentina and Chile, inferred from historical records and tree-ring reconstructed precipitation, Palaeogeogr. Palaeoclimatol. Palaeoecol., 281, 334-344, doi:10.1016/j.palaeo.2008.01.039.

Luterbacher, J., et al. (2002), Reconstruction of sea level pressure fields over the eastern North Atlantic and Europe back to 1500, Clim. Dyn., $18,545-561$.

Luterbacher, J., et al. (2004), European seasonal and annual temperature variability, trends, and extremes since 1500, Science, 303, 1499-1503, doi:10.1126/science. 1093877

Magrin, G., et al. (2007), Latin America, in Climate Change 2007: Impacts, Adaptation and Vulnerability. Contribution of Working Group II to the Fourth Assessment Report of the Intergovernmental Panel on Climate Change, edited by M. L. Parry et al., pp. 581-615, Cambridge Univ. Press, Cambridge, U. K.

Mitchell, T. D., and P. D. Jones (2005), An improved method of constructing a database of monthly climate observations and associated high-resolution grids, Int. J. Climatol., 25, 693-712, doi:10.1002/ joc. 1181 .
Moy, C. M., et al. (2009), Climate change in southern South America during the last two millennia, in Past Climate Variability in South America and Surrounding Regions, edited by F. Vimeux et al., pp. 353-393 doi:10.1007/978-90-481-2672-9 15, Springer, New York.

Neukom, R., M. del Rosario Prieto, R. Moyano, J. Luterbacher, C. Pfister, R. Villalba, P. D. Jones, and H. Wanner (2009), An extended network of documentary data from South America and its potential for quantitative precipitation reconstructions back to the 16th century, Geophys. Res. Lett., 36, L12703, doi:10.1029/2009GL038351.

Neukom, R., et al. (2010), Multiproxy summer and winter surface air temperature field reconstructions for southern South America covering the past centuries, Clim. Dyn., doi:10.1007/s00382-010-0793-3.

Pauling, A., et al. (2006), Five hundred years of gridded high-resolution precipitation reconstructions over Europe and the connection to largescale circulation, Clim. Dyn., 26, 387-405, doi:10.1007/s00382-0050090-8.

Peterson, T. C., and R. S. Vose (1997), An overview of the global historical climatology network temperature database, Bull. Am. Meteorol. Soc., 78 , 2837-2849, doi:10.1175/1520-0477(1997)078<2837:AOOTGH >2.0. $\mathrm{CO} ; 2$

Piovano, E. L., et al. (2009), Hydrological variability in South America below the Tropic of Capricorn (Pampas and Patagonia, Argentina) during the last $13.0 \mathrm{Ka}$, in Past Climate Variability in South America and Surrounding Regions, edited by F. Vimeux et al., pp. 323-351, doi:10.1007/978-90-481-2672-9_14, Springer, New York.

Rutherford, S., et al. (2005), Proxy- $\bar{b}$ ased Northern Hemisphere surface temperature reconstructions: Sensitivity to method, predictor network, target season, and target domain, J. Clim., 18, 2308-2329, doi:10.1175/ JCLI3351.1.

Scherrer, S. C., and C. Appenzeller (2006), Swiss Alpine snow pack variability: Major patterns and links to local climate and large-scale flow, Clim. Res., 32, 187-199, doi:10.3354/cr032187.

Smerdon, J. E., et al. (2010), A pseudoproxy evaluation of the CCA and RegEM methods for reconstructing climate fields of the last millennium, J. Clim., doi:10.1175/2010JCLI3328.1, in press.

van der Schrier, G., et al. (2007), Exploring an ensemble approach to estimating skill in multiproxy palaeoclimate reconstructions, Holocene, 17 119-129, doi:10.1177/0959683607073294

Villalba, R., et al. (1997), Sea-level pressure variability around Antarctica since AD 1750 inferred from subantarctic tree-ring records, Clim. Dyn. 13, 375-390, doi:10.1007/s003820050172.

Wahl, E. R., and C. M. Ammann (2007), Robustness of the Mann, Bradley, Hughes reconstruction of Northern Hemisphere surface temperatures: Examination of criticisms based on the nature and processing of proxy climate evidence, Clim. Change, 85, 33-69, doi:10.1007/s10584-0069105-7.

Wilson, R., et al. (2010), Reconstructing ENSO: The influence of method, proxy data, climate forcing and teleconnections, J. Quat. Sci., 25, 62-78, doi: $10.1002 /$ jqs. 1297

Xoplaki, E., J. Luterbacher, H. Paeth, D. Dietrich, N. Steiner, M. Grosjean, and H. Wanner (2005), European spring and autumn temperature variability and change of extremes over the last half millennium, Geophys. Res. Lett., 32, L15713, doi:10.1029/2005GL023424.

J. Esper, Department of Geography, Johannes Gutenberg University, D-55099 Mainz, Germany.

D. Frank, Swiss Federal Research Institute WSL, Zürcherstrasse 111, CH-8903 Birmensdorf, Switzerland.

M. Grosjean, R. Neukom, and H. Wanner, Institute of Geography, Climatology and Meteorology, University of Bern, Hallerstrasse 12, CH-3012 Bern, Switzerland. (neukom@giub.unibe.ch)

P. D. Jones, Climatic Research Unit, School of Environmental Sciences, University of East Anglia, Norwich NR4 7TJ, UK

M. Küttel, Department of Earth and Space Sciences, University of Washington, Box 351310, Seattle, WA 98195, USA.

L. Lopez and R. Villalba, Instituto Argentino de Nivología y Glaciología y Ciencias Ambientales, CONICET, Av. Dr. Adrián Ruiz Leal s/n, C.C. 330, 5500 Mendoza, Argentina.

J. Luterbacher, Department of Geography, Climatology, Climate Dynamics and Climate Change, Justus Liebig University Giessen, Senckenbergstrasse 1, D-35390 Giessen, Germany. 